\title{
SPACs Create New Opportunities to Exit Your Business
}

\author{
David Deeds (University of St. Thomas)
}

KEYWORDS: Entrepreneurship, Finance, Mergers and Acquisitions.

Everybody from former CEOs to former Speaker of The House Paul Ryan to Shaq to Colin Kaepernick are all leading Wall Street's latest fad - The Special Purpose Acquisition Corporation (SPAC). Approximately 400 SPACs now control over $\$ 120$ billion in capital, and more than 100 others are in the pipeline.

You may wonder: What is a SPAC and what's it going to do for my company? The short answer: Wall Street's latest fad may make this the perfect opportunity to exit your business.

SPACs are publicly traded blank slates, created to acquire private companies and thus make them publicly traded companies. They are often referred to as "Blank Check Companies" because they are a company with no commercial operations that is formed strictly to raise capital through an initial public offering (IPO) for the purpose of acquiring an existing company. They are essentially vehicles to create reverse mergers that avoid much of the increased regulatory burden placed on companies attempting an IPO by Sarbanes-Oxley and other recent changes to regulation.

\section{On an Acquisition Roll}

SPACs raised $\$ 3.2$ billion in 2016, \$19.6 billion in 2019 and over $\$ 120$ billion since the beginning of 2020 . SPAC's have acquired, or are in the process of acquiring, Lucid and Xos, Tesla Motors new rivals. A SPAC even acquired Virgin Galactic in October 2019. They have acquired cannabis companies, construction companies, logistics companies, biotechs and pretty much everything else. They have acquired young and old businesses, tech companies and very traditional companies. They are buying family-owned businesses, tech startups and everything in between.

Currently, the smallest price paid for an acquisition appears to be about $\$ 50$ million, but given the number of new SPACs I expect to see that go lower as SPAC's

begin pursuing a rollup strategy of combining several smaller but related firms into one larger public company.

The process of creating a SPAC is pretty straightforward. Essentially a management team puts together a corporate shell and goes through the process of issuing an IPO for a company whose sole purpose is to acquire private companies with the capital raised through the IPO. The IPO process is much quicker, easier and cheaper for SPACs because they are very simple entities at this point, requiring less expenditures on accounting, legal work, etc. The average SPAC raises about $\$ 50$ million, but the size is growing and the largest has been $\$ 4$ billion. Once they go public and acquire capital, the money raised in the IPO is placed in an interest-bearing trust account. These funds cannot be disbursed except to complete an acquisition or to return the money to investors if the SPAC is liquidated.

The SPAC -- and here is the key for entrepreneurs and family business owners -- has just 24 months to use the capital raised to acquire companies or it is returned to the investors. So, since the beginning of 2020 over $\$ 120$ billion of capital has been raised to acquire companies, with more to come. The clock is ticking on all of these funds, so the acquisition market for private companies is likely to get very hot.

\section{Opportunities for Startups and Family Firms}

So what does this mean for entrepreneurs and family businesses? It is very likely to be a strong seller's market for companies in 2021 and at least through 2022. There is already an estimated $\$ 4.5$ trillion invested in Private Equity (PE) funds, and an estimated $\$ 600$ billion was raised by PEs in 2019 . It is estimated that approximately a third of that money, and perhaps as much as half, will be employed in acquisitions of private companies. So even without SPACs the market for acquisitions was already frothy and a definite seller's market. Drop in another $\$ 120$ billion in capital in less

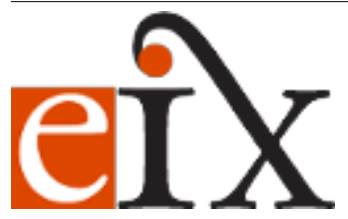

Copyright ( ) 2021 The Authors. Entrepreneur \& Innovation Exchange is published at EIX.org. This is an open access article under the terms of the Creative Commons Attribution-NoDerivs License, which permits use and distribution in any medium, provided the original work is properly cited and no modifications or adaptations are made. View EIX.org Authorship Terms at https://eix.org/terms 
than 18 months with a 24 month investment deadline, and the value of private companies is likely to skyrocket.

So as an entrepreneur growing a venture or the owner of family business that might be ready to be sold, what should you do? First, prepare the company for the sale. Make sure the books are clean and customers are happy. Hit some milestones and targets so you have accomplishments to tout.

Second, scout the terrain. The founders of a SPAC are usually scouting for companies well before the actual offering. Legally, they cannot disclose targets or discuss them with potential investors prior to the SPAC going public, or it must be disclosed and complicates the IPO process and essentially eliminates any advantage of using a SPAC. Look for announcement of SPACs that are being formed. Check to see what existing SPACs are focused on your industry and market that may have capital to put into play. There are several sites that are tracking SPACs, so a quick Google search will be a place to start. Consider contacting an investment bank or business broker to discuss if your business might be attractive to SPACs and if they know of any SPACs forming that might have an interest.

The bottom line is that a large amount of capital is suddenly flowing into the market for private companies and the values of those companies are likely to be going up, which makes 2021-22 a period to seriously consider selling your company. 